\title{
Giant retinal tears resulting from eye gouging in rugby football
}

\author{
I G M Duguid, P K Leaver
}

\begin{abstract}
A 29 year old myopic man sustained two separate giant retinal tears in his right eye following deliberate eye gouging during a rugby tackle. These were successfully repaired by vitrectomy and intraocular silicone oil injection. Although the postoperative course was complicated by pupil block glaucoma, he regained corrected visual acuity of $6 / 5$ after oil removal. This injury highlights the potentially sight threatening nature of this type of rugby injury and the importance of early referral for specialist treatment.

(Br F Sports Med 2000;34:65-66)
\end{abstract}

Keywords: eye; retina; rugby

Giant retinal tears are those that extend through $90^{\circ}$ and result in a large posterior flap of retina that is mobile from the surrounding vitreous. ${ }^{1}$ They may be idiopathic (usually in high myopes), result from blunt or penetrating ocular trauma, or occur in certain vitreoretinal dystrophies. Retinal detachment occurs as fluid passes through the large tear and accumulates under the retina. Central vision may be lost if the retinal detachment extends to involve the fovea, or the torn retina folds over on itself to cover the fovea. Unlike the case of retinal dialyses (which commonly result from blunt trauma), the vitreous is detached posteriorly and the surgical outcome is uncertain because of the risk of late scar tissue formation. Surgical
Vitreoretinal Surgical Service, Moorfields

Eye Hospital, City 2PD, United Kingdom I G M Duguid P K Leaver

Correspondence to: Mr I G M Duguid.

Accepted for publication 28 July 1999

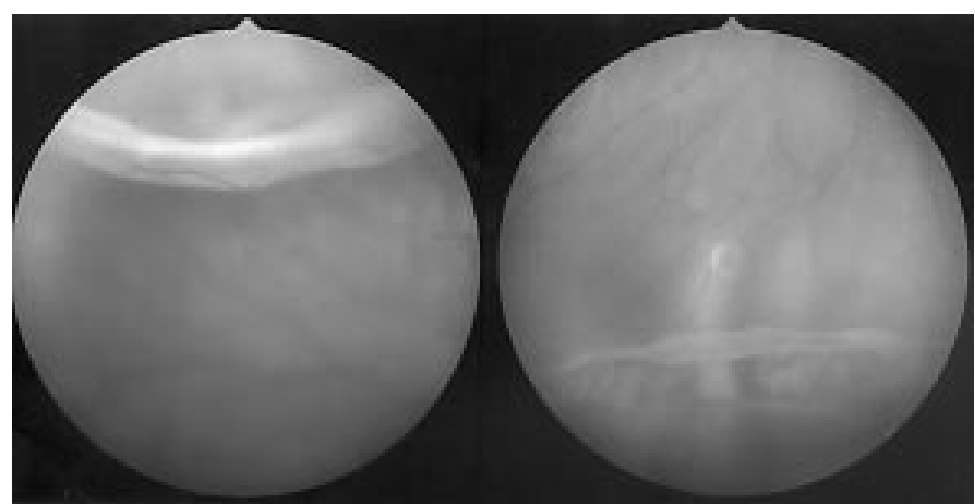

Figure 1 Fundus photographs of the right peripheral retina showing the superior (left) and inferior (right) giant retinal tears. Note the superior retinal flap folding posteriorly and the elevated anterior flap of the inferior tear. repair requires vitrectomy, laser or cryo retinopexy, and injection of silicone oil or gas to tamponade the retinal break. Visual recovery is variable, depending on the extent of macular damage and the development of complications after the operation.

Although serious injury to the eye is uncommon while playing rugby, ${ }^{2}{ }^{3}$ the eye is particularly vulnerable to injury as a result of punching or gouging. The potential for visual damage from eye gouging is probably well appreciated by players, and fortunately this practice is rare. This case highlights the serious sight threatening sequelae of such an injury.

\section{Case report}

A 29 year old myopic man presented with rapid onset of an inferior visual field defect in his right eye. He gave a six day history of floaters in that eye, occurring immediately after a rugby tackle in which his right eye was deliberately gouged with an opponent's thumb, the pressure being maintained for several seconds. He had suffered no previous ocular trauma. The left eye was normal. His right visual acuity was $6 / 6$ corrected and there was a mild anterior uveitis. Funduscopy showed both a superior and an inferior giant retinal tear and associated retinal detachment without macular involvement (figs 1 and 2). Surgery to repair the retina was undertaken using vitrectomy, intraocular silicone oil injection, laser photocoagulation, and inferior scleral buckling.

After the operation the retina was attached, but six weeks later the patient developed an episode of acute angle closure glaucoma secondary to a droplet of silicone oil migrating forwards into the anterior chamber and blocking the pupil. Emergency admission was required to control the intraocular pressure which was elevated to $60 \mathrm{~mm} \mathrm{Hg}$ (normally $<21 \mathrm{~mm} \mathrm{Hg}$ ). Medical treatment, including intravenous mannitol, was unsuccessful, and drainage of anterior chamber silicone oil by corneal paracentesis was required. The remainder of the oil was removed electively two months after the operation.

Although the visual acuity of the patient ultimately improved to $6 / 5$ (corrected with glasses), he suffers from some minification of the image in the right eye. 


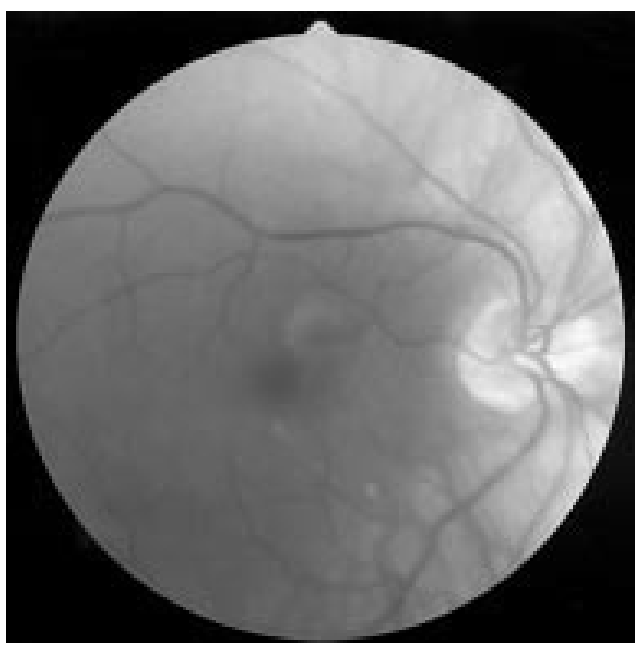

Figure 2 Photograph showing that the posterior pole of the fundus appears normal.

\section{Discussion}

This case illustrates the severity of retinal damage that can result from a gouging injury, easily inflicted as a form of foul play during rugby. That the giant retinal tear was a direct result of the eye gouging is beyond reasonable doubt, given the immediate onset of floaters after the injury and the diagnosis of giant retinal tears a few days later. Fortunately the patient presented early, before his central vision was affected, made a full recovery from the surgery and its complications, and achieved an excellent visual outcome. His visual acuity may have been a lot worse had he developed a macular retinal detachment or complications such as secondary intraocular scarring (proliferative vitreoretinopathy).

Giant retinal tears are an extreme form of retinal tear which can occur as a result of blunt ocular trauma ${ }^{4}$ sustained in sport, for example by impact with a ball, bat, racket, part of an opponent's body or, as in this case, from deliberate ocular injury. Other types of retinal break include smaller peripheral flap tears, paravascular radial slit tears, ${ }^{5}$ retinal dialyses (disinsertion of the peripheral retina at its anterior border),${ }^{6}$ irregular breaks in necrotic retina, ${ }^{7}$ and macular holes. ${ }^{8}$ Giant tears and dialyses are believed to result from transverse distension of the globe as it is compressed anteroposteriorly. ${ }^{9}$ An eye gouging injury could equally cause other ocular sequelae such as dislocation of the lens, vitreous haemorrhage, retinal commotion, globe rupture, traumatic optic neuropathy, or fracture of the orbital floor. ${ }^{10}$

Occasionally, serious foul play incidents in rugby are reported in the media. A study of catastrophic eye injuries occurring in rugby union and league players in New South Wales over a 16 year period disclosed claims for financial compensation for permanent visual impairment in 26 cases, five of which resulted from injuries that appeared to be due to intentional gouging. Others arose from blows with fists, elbows, or knees. ${ }^{11}$

This case graphically illustrates the potentially severe consequences of eye gouging, and team doctors and physiotherapists should bring this to the attention of players, referees, and coaches involved in contact sports. The favourable outcome provides a timely reminder that anyone complaining of persistent ocular floaters after a blow directly to the eye or head should be examined by an ophthalmologist within 24 hours.

1 Scott JD. Giant tear of the retina. Transactions of the Ophthalmalogical Society of the UK 1975;95:142-4.

2 Jokoer I, Noakes TD, A high rate of injury during the 1995 Rugby World Cup. S Afr Med f 1998;88:45-7.

3 MacEwen CJ. Sport associated eye injury: a casualty department survey. Br f Ophthlmol 1987;71:701-5.

4 Aylward GW, Cooling RJ, Leaver PK. Trauma induced retinal detachment associated with giant retinal tears. Retina 1993;13:136-41.

5 Cooling RJ. Traumatic retinal detachment mechanisms and management.Transactions of the Ophthalmalogical Society of the UK 1986;105:575-9.

6 Kennedy CJ, Parker CE, McAllister IL. Retinal detachment caused by retinal dialysis. Aust N Z F Ophthalmol 1997;25: 25-30.

7 Johnston PB. Traumatic retinal detachment. Br f Ophthalmol 1991;75:18-21.

8 Cox MS, Schepens CL, Freeman HM. Retinal detachment due to ocular contusion. Arch Ophthalmol 1966;76:678-85.

9 Weidenthal DT, Schepens CL. Peripheral fundus changes associated with ocular contusion. Am $f$ Ophthalmol associated with

10 Jones NP. Eye injuries in sport. F R Coll Surg Edinb 1993;38: 127-33.

11 Lawson JS, Rotem T, Wilson SF. Catastrophic injuries to the eyes and testicles in footballers. Med F Aust 1995;163: $242-4$.

\section{Take home message}

Eye gouging can easily cause sight threatening ocular damage. Players, coaches, and administrators should be aware of its risks. Any sportsman complaining of floaters after a blow to the eye should be referred to an ophthalmologist within 24 hours.

\section{Commentary}

Retinal detachment is an uncommon condition. At the most, $10 \%$ of all detachments are attributable to previous injury. Such detachments are not due to bumps or blows to the head but result from direct force applied to the eye resulting in deformation of the globe. An increasing number of trauma induced retinal detachments result from sports injuries and represent a greater proportion of complex detachments such as those with associated giant retinal breaks. Not uncommonly other factors play a part in the development of the detachment such as myopia. In many sports, serious injury is the consequence of foul play such as thumbing injuries in boxing as well as other forms of eye gouging as in the reported case. Outlawing certain types of play by simply highlighting their occurrence or legislative action can do much to prevent these sight threatening injuries. 